\title{
Objetos Digitais de Aprendizagem no Ensino de Física Básica: Um estudo de caso com simuladores virtuais em uma escola de ensino público estadual
}

\author{
Arley Carvalho - CERTEC / IFMA - arley251@gmail.com \\ Ariel Teles - IFMA - ariel.teles@ifma.edu.br \\ Davi Viana - UFMA - davi.viana@1sdi.ufma.br \\ Francisco José Silva - UFMA - fssilva@1sdi.ufma.br \\ Luciano Coutinho - UFMA - luciano.rc@ufma.br \\ Silmar Teixeira - UFPI - silmarteixeira@ufpi.edu.br
}

Resumo. Este trabalho discute as dificuldades que os estudantes enfrentam no estudo da Física e investiga a influência do uso de Objetos Digitais de Aprendizagem (ODAs), especificamente os simuladores virtuais, partindo da hipótese que contribuem para o aumento da motivação e interesse dos estudantes. Para isso, realizou-se em uma escola pública a aplicação de um questionário que forneceu informações sobre o contexto escolar e as aspirações deles quanto às metodologias de ensino. Após a aplicação do questionário, foi analisado como os simuladores virtuais disponíveis no portal PhET influenciam os estudantes, em que ficou evidente que os ODAs do tipo simuladores virtuais podem contribuir para a aprendizagem dos alunos e não devem ser usados como uma solução única e definitiva para os problemas de aprendizagem em Física.

Palavras-chave: Ensino de Física Básica; Objetos Digitais de Aprendizagem; Simuladores Virtuais.

\section{Digital Learning Objects in Basic Physics Teaching: A case study with virtual simulators in a public school}

\begin{abstract}
This paper discusses the difficulties that students face while studying Physics and investigates the influence of the use of Digital Learning Objects (DLOs), specifically the virtual simulators, starting from the hypothesis that they contribute to the increase of student motivation and interest. For this, a questionnaire was provided to a public high school with information about the school context and their aspirations regarding teaching methodologies. After the application of the questionnaire, it was analyzed how the virtual simulators available in the PhET portal influence students, in which it became apparent that virtual simulator DLOs can contribute significantly to student learning and should not be used as a unique and definitive solution for learning issues in physics.
\end{abstract}

Keywords: Basic Physics Teaching; Digital Learning Objects; Virtual Simulators.

\section{Introdução}

A escola e o professor assumem um papel essencial na reflexão do conhecimento adquirido e na motivação pela busca de novos saberes por parte dos alunos. Entretanto, à medida que a escola, professor e aluno se engajam na busca pelo saber, surgem desafios próprios do processo de ensino-aprendizagem que há décadas têm sido motivo de intensa pesquisa na área da educação. Em especial quanto a dinamicidade, que cobra dos integrantes do processo um constante esforço em progredir e adquirir novas habilidades. Um exemplo disso pode ser visto com a adoção do uso das Tecnologias de Informação e Comunicação - TICs (Matos et al., 2019). 
Neste contexto, tem tornado-se clara a necessidade de mudanças igualmente intensas, nos papéis e atitudes, tanto do professor, como dos alunos, exigindo que a educação não fique às margens das transformações tecnológicas. Contudo, o que verifica-se atualmente é um pouco diferente, sobretudo em disciplinas que envolvem considerável grau de abstração e imaginação como é o caso da Física, que muitas vezes acaba sendo resumida às fórmulas, conceitos e teorias, carecendo do pluralismo metodológico, tão vital ao complexo processo de ensino. Esse modelo de ensino de Física, evidentemente, não produz alunos críticos e autônomos. Ao contrário, seu resultado são alunos desmotivados e passivos (Moraes, 2009).

$\mathrm{Na}$ área de Física, a experimentação é relevante, sua ausência contribui para o desinteresse dos estudantes e promove o uso da metodologia expositiva, focada em conceitos e métodos matemáticos. Apesar do reconhecimento do papel basilar da experimentação para o estudo da Física, professores e alunos esbarram em alguns problemas, como aulas demasiadamente teóricas. Assim, a questão que surge é: como suplantar, ou pelo menos amenizar, algumas das dificuldades que surgem no processo de ensino-aprendizagem de Física? Para auxiliar a dinamizar as aulas, incluindo aspectos tecnológicos, pode-se utilizar Objetos Digitais de Aprendizagem (ODAs). Os ODAs podem ser qualquer recurso educacional que faça uso de tecnologia para apoiar o aprendizado dos estudantes (Martins e Basso, 2018).

Com esse trabalho, realizou-se intervenções na realidade de estudantes do ensino médio por adotar estratégias de ensino baseadas na utilização de ODAs que pudessem despertá-los para a compreensão dos conceitos e fenômenos físicos sobre uma ótica lúdica e moderna. Especificamente, esta pesquisa visou identificar as principais dificuldades encontradas pelos alunos ao estudar Física. Adicionalmente, ela buscou verificar como o uso de ODAs influencia a motivação e a aprendizagem dos estudantes frente às aulas de Física.

O restante do artigo é organizado como segue. A Seção 2 aborda a fundamentação teórica e problemática. A Seção 3 detalha a metodologia utilizada neste estudo, a qual possibilitou a obtenção dos resultados que foram apresentados e discutidos na Seção 4. Por fim, a Seção 5 conclui o trabalho e destaca as perspectivas de trabalhos futuros.

\section{Necessidade de Remodelação do Ensino}

Evidentemente, cada geração de estudantes possui características e necessidades diferentes. Segundo Fardo (2013), a velocidade e o alcance em que as informações são compartilhadas atualmente mudaram o comportamento dos alunos em praticamente todos os campos, em especial, na forma como eles interagem com o mundo e com eles mesmos. Diferentemente dos estudantes que se formaram há algumas décadas, os alunos atuais nasceram cercados pelas TICs. Segundo Fardo (2013), os alunos desta geração estão imersos em um ambiente ubíquo, com pleno acesso à informação, em especial na Internet, ultrapassando as fronteiras espaço-temporais que há muito tempo foram estabelecidas sobre a forma de criar, compartilhar e consumir as informações para gerar conhecimento.

Quando se trata de disciplinas pertencentes às ciências da natureza, em destaque a Física, com suas nuances e abstrações próprias, pesquisas apontam para a importância de ressignificar os papéis de alunos e professor em sala de aula. Trabalhos como os de Mortimer e Scott (2002) e Bozelli e Nardi (2012) propõem que os estudantes possam atuar como protagonistas no processo de ensino-aprendizagem, não se limitando apenas 
a um espectador que deve captar e reproduzir o que é dito. Seguindo a mesma tendência, Monteiro (2016) cita diversos pesquisadores que defendem que as aulas de ciências devem estimular o protagonismo dos estudantes e sugerem que a intervenção didática permite que os estudantes discutam suas concepções, levantem e testem suas hipóteses, construam argumentos explicativos em função dos dados obtidos em seus experimentos e reflitam sobre o significado da Ciência e do fazer científico.

\subsection{Dificuldades no processo de ensino-aprendizagem de Física}

O cenário do ensino básico brasileiro, especificamente, do ensino de Ciências, além de claramente crítico, é prejudicial. Em 2005, o documento intitulado "Ensino de Ciências: o futuro em risco" (UNESCO, 2005), destacou que a falta de uma formação de qualidade em Ciências agravaria as desigualdades do país e resultaria em um atraso no mundo globalizado. Uma vez que o ensino de Física é fundamental para uma formação científica de qualidade, as dificuldades no seu ensino são aspectos a serem constantemente investigados.

Muitos professores apontam como uma dificuldade a deficiência na formação dos estudantes que ingressam no ensino médio, sobretudo em Matemática. O Anuário Brasileiro da Educação Básica mostra claramente essa realidade (Cruz e Monteiro, 2019). Segundo seus dados, apenas $7 \%$ dos estudantes do $9^{\circ}$ ano do ensino fundamental possuem aprendizado adequado em Matemática ao passo que o resultado dos alunos da $3^{\text {a }}$ série do ensino médio foi de 3,2\%. Essa deficiência é extremamente preocupante, visto que a Matemática assume um papel fundamental dentro do ensino de Física, para a análise e construção de modelos que envolvem fenômenos físicos.

É provável que dentre as dificuldades no processo de ensino-aprendizagem de Física, a que ganhe o maior destaque, especialmente sobre a ótica dos alunos, seja o uso da metodologia expositiva e centrada na operacionalização matemática, deixando a experimentação longe do processo. Neste tipo de metodologia, deixa-se de lado o conceito central da teoria de aprendizagem de David Ausubel - a aprendizagem significativa. Para Ausubel (2003) a aprendizagem é relacional, ela está relacionada com os conhecimentos prévios e experiências vividas pelo indivíduo. A dificuldade que muitos estudantes têm ao estudar Física está em fazer a relação entre o conhecimento que está lhes sendo apresentado e o conjunto de experiências que formou ao longo de sua vida. É importante lembrar que a Física é uma ciência que visa compreender os fenômenos da natureza, a relação do homem com o mundo e o universo, bem como melhorar as condições de vida da sociedade por meio da tecnologia.

\subsection{Uso de ODAs como propulsores de ensino}

Com o desenvolvimento acelerado das TICs nas décadas recentes, diversos recursos aplicados à educação passaram a ser criados e estudados. Dentre estes, os ODAs têm se mostrado como grandes aliados aos professores e alunos. Segundo Valentini e Bisol (2018), o conceito de ODA é bastante amplo, o que "permite que as ferramentas sejam pensadas e desenvolvidas de diferentes formas". São exemplos os tutoriais, podcasts, jogos, animações, simuladores e videoaulas. No contexto desta pesquisa o termo será usado para referir-se sobretudo às soluções de software educativas com enfoque construcionista, tais como os simuladores, micromundos, sistemas de autoria e de programação. 
No processo de ensino-aprendizagem, o uso de ODAs traz consigo diversos benefícios, visto que, em sua maioria, permitem um ensino mais independente, interativo, dinâmico e personalizado. Outra vantagem do uso de ODAs, em especial os que se enquadram na categoria de simuladores, reside no fato destes permitirem aos estudantes a familiarização com situações que na prática envolveriam risco, demandariam muito tempo, envolveriam muito custo ou que seriam impossíveis. $\mathrm{O}$ aspecto colaborativo também aparece em produtos de software de simulação, o que faz dessa ferramenta uma excelente oportunidade para os professores estimularem em seus alunos. Além da colaboração, também há a coletividade e as relações interpessoais.

A utilização de ODAs no ensino de Física é estimulada e trabalhos sobre este tema têm aumentado em anos recentes (Girwidz et al., 2019). Por exemplo, Araújo et al. (2015) investigaram o uso de um software educacional no ensino de eletricidade, destacando a melhoria da percepção dos estudantes sobre outros conteúdos. Zara (2011), em sua pesquisa, refletiu sobre a eficácia do uso de um ambiente virtual no ensino de Física. Sobre os benefícios, trabalhos como os de Greis e Reategui (2010), Savi e Ulbricht (2008) e Nascimento et al. (2016), destacaram as vantagens do uso de ODAs como instrumentos de ensino. Além de continuar as pesquisas sobre esse importante tema, este trabalho, diferente dos acima destacados, investigará a possibilidade do uso de simuladores virtuais minimizarem as dificuldades no processo de ensino-aprendizagem de Física.

\section{Metodologia}

Primeiramente, delimitou-se o campo de pesquisa deste trabalho ao Centro de Ensino Joaquim Soeiro de Carvalho, uma escola pública estadual de ensino médio da cidade de Barreirinhas, no Estado do Maranhão. Esta escola possui cerca de 1.100 (um mil e cem) estudantes em sua sede, distribuídos nos três turnos. As ações deste trabalho concentraram-se em alunos voluntários das turmas do $3^{\circ}$ ano do ensino médio dos turnos matutino e vespertino.

A coleta de dados da pesquisa foi realizada em duas etapas. Na primeira, 65 alunos responderam a um questionário sobre sua realidade e seus anseios quanto às metodologias educacionais disponíveis ao estudar Física. A construção do questionário foi baseada no trabalho de Coelho et al. (2019).

$\mathrm{Na}$ segunda etapa, 19 estudantes foram experimentar alguns simuladores virtuais disponibilizados pelo portal $\mathrm{PhET}^{1}$. Esta etapa limitou-se a essa amostra devido a limitações na infraestrutura do Laboratório de Informática (LI) da instituição de ensino. O Kit para Montar Circuito DC - Lab Virtual foi a simulação escolhida para integrar esta pesquisa. Esta simulação objetiva explorar as relações básicas de eletricidade e, para isso, ela aborda os seguintes tópicos da disciplina de Física: Circuitos em Série, Circuito Paralelo, Lei de Ohm e Lei de Kirchoff. Através deste ODA de simulação é possível construir circuitos com resistores, lâmpadas, baterias, fusíveis e interruptores, determinar se os objetos do cotidiano são condutores ou isoladores, e fazer medições com um amperímetro e um voltímetro.

Para finalizar, os estudantes participantes da segunda etapa seguiram um roteiro ${ }^{2}$ que os norteou na utilização do simulador, ao mesmo tempo que fornecia dados relativos à sua aprendizagem.

\footnotetext{
${ }^{1}$ https://phet.colorado.edu/pt_BR/simulations/category/physics

${ }^{2}$ http://bit.ly/2RAgwJl 


\section{Resultados e Discussões}

Na etapa 1, para compreender a afinidade dos estudantes com o estudo de Física, primeiramente, houve o questionamento se eles gostavam de estudá-la. Por meio da Figura 1 pode-se constatar que $42 \%$ dos alunos gostam pouco e $8 \%$ não tem afinidade nenhuma pela disciplina. A pouca atração poderia se dar pela falta de reconhecimento da relevância da mesma. Porém, o gráfico da Figura 2 indica que não é esse o caso, visto que $71 \%$ deles se apercebem da importância do seu estudo. Esse resultado indica que há outro motivo para muitos alunos não terem afinidade com a disciplina.
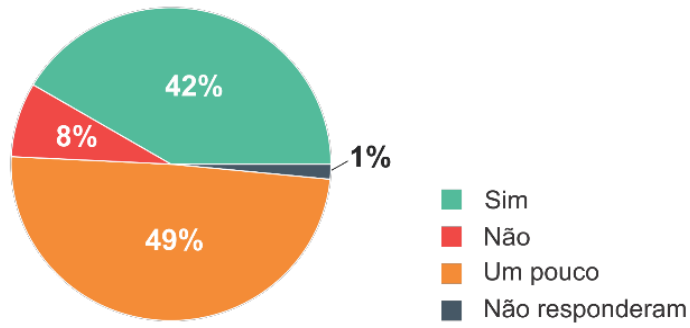

Figura 1 - Percentual de alunos que gostam de estudar Física.

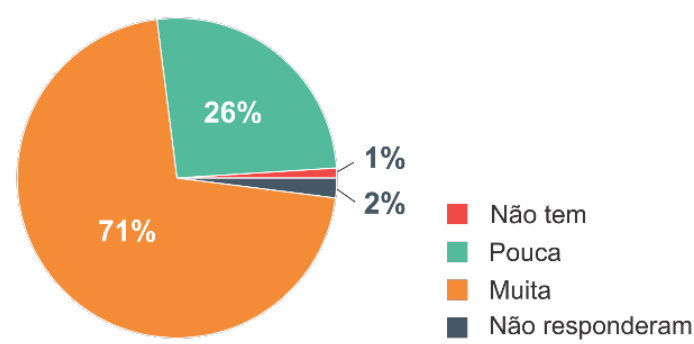

Figura 2 - Percepção da importância do estudo da Física.

Após isso, a pesquisa investigou quanto ao uso de recursos digitais por parte dos docentes. O gráfico da Figura 3 mostra um dado animador nesse sentido, visto que $82 \%$ dos estudantes relataram que, ao trabalhar o conteúdo, seus professores utilizavam recursos digitais. Porém, quando se trata do uso específico do LI da escola e, consequentemente, dos recursos que este pode oferecer, o gráfico da Figura 4 indica um cenário menos animador, pois $81 \%$ dos alunos afirmaram que o usam ocasionalmente para ampliar seus conhecimentos e $15 \%$ nunca o usaram.

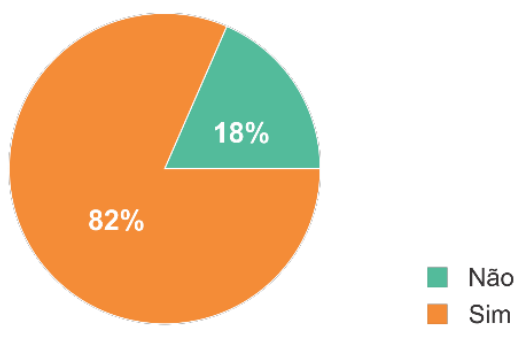

Figura 3 - Uso de recursos digitais pelo professor.

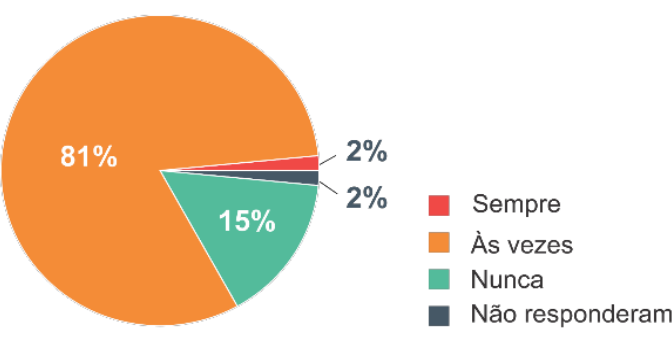

Figura 4 - Uso do laboratório de informática.

A preocupação com esses resultados deve-se principalmente devido às possibilidades oferecidas pelo uso do LI, visto que por meio dele os estudantes contam com um rico leque de aplicativos educacionais que, se corretamente usados, poderiam enriquecer seu conhecimento, além de reforçar a cooperação e a interatividade, tão presentes na sociedade digital. Outra questão é que o uso mais frequente da Internet do LI poderia dar a eles a oportunidade de consumir informações de qualidade, por exemplo, ao acessar sites e cursos de Educação a Distância (EaD) de instituições V. $17 \mathrm{~N}^{\mathrm{o}}$ 3, dezembro, 2019 RENOTE 
renomadas. Outro fator relevante é o alto investimento, sobretudo financeiro, que foi realizado a fim de que a escola pudesse possuir um LI em plenas condições de funcionamento, para que seus recursos não sejam explorados em benefício dos alunos. Evidentemente, não se espera que o LI seja utilizado em todas as aulas, pois essa estratégia iria contra a concepção da pluralidade metodológica, mas sim que o LI pudesse ser melhor explorado diante dos recursos e possibilidades que oferece.

Outro questionamento feito aos alunos foi quanto a relação dos conteúdos estudados em Física com a sua realidade e cotidiano. Apesar de 66\% dos entrevistados conseguirem perceber a relação do que estudavam com o seu cotidiano e as tecnologias que os cercavam, quase um terço dos estudantes (31\%) afirmaram ver pouca relação entre eles, como revela o gráfico da Figura 5. Esse percentual causa preocupação, porque a maioria dos temas estruturadores que fazem parte das orientações educacionais dos PCN+ (BRASIL, 2006) envolvem tecnologias e fenômenos físicos bem visíveis ou conhecidos. Uma possibilidade para a pouca percepção destes estudantes é a dificuldade que alguns professores de Física têm em associar o que ensinam com o que seus alunos vivenciam. Entretanto, não é difícil encontrar materiais didáticos que destaquem a praticidade de cada conteúdo, permitindo ao professor contextualizar melhor suas aulas e, assim, facilitar a aprendizagem de seus alunos. O resultado do aluno não conseguir relacionar o conhecimento que lhe foi apresentado com algo que já faça parte do seu "acervo intelectual" ou histórico de experiências, recai diretamente no prejuízo da aprendizagem significativa de David Ausubel. A responsabilidade de guiar o processo cognitivo de aprendizagem dos alunos é do professor, portanto, cabe a ele não apenas sondar, por meio de testes diagnósticos no início do ano letivo, mas também levar em conta os conhecimentos e experiências estudantis ao elaborar e executar suas estratégias de ensino ao longo do ano.

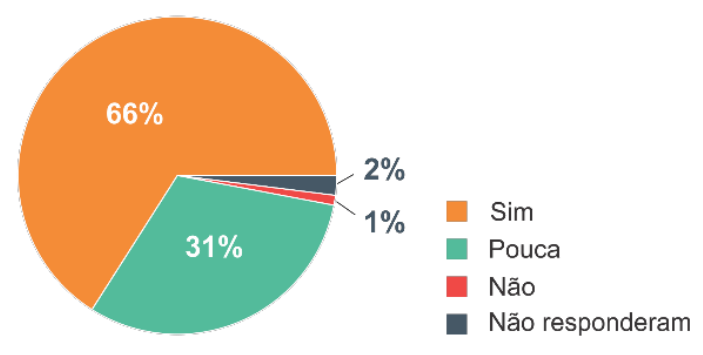

Figura 5 - Percepção dos estudantes quanto a relação Física escolar/cotidiano.

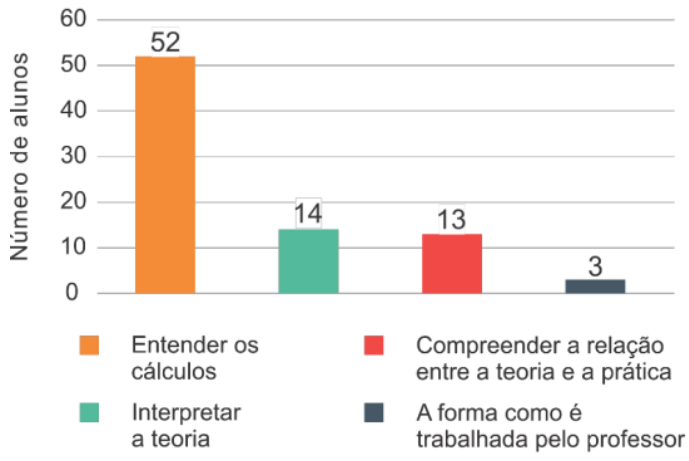

Figura 6 - Principais dificuldades no estudo de Física.

Este trabalho também teve a preocupação de investigar quais eram as principais dificuldades enfrentadas pelos participantes ao estudar Física. É importante destacar que nesse questionamento os alunos podiam listar quantas dificuldades desejassem. Um detalhe que chamou atenção no gráfico da Figura 6 é que, na visão da maioria dos alunos, a sua dificuldade em estudar a disciplina não se deve ao modo como o professor trabalha o conteúdo, mas sim em entender os cálculos. Na metodologia de ensino tradicional, a relação professor-aluno é verticalizada, assim, a culpa pela dificuldade de aprendizagem costuma recair sobre o educando. Entretanto, visto que o conceito moderno do processo de ensino-aprendizagem deve ser o horizontal (professor $\leftrightarrow$ aluno), 
é importante que não apenas o bônus, mas também o ônus sejam compartilhados. Isso, porém, não foi percebido na Figura 6, pois a diferença entre o número de alunos que têm dificuldade em entender os cálculos efetuados e a quantidade de alunos que apontam a metodologia empregada pelo professor como sua maior dificuldade é significativamente grande. A Figura 6, todavia, corrobora a realidade negativa indicada no Anuário Brasileiro da Educação Básica (Cruz e Monteiro, 2019), de que poucos estudantes possuem aprendizado adequado em Matemática. Como o número de alunos que indicaram o entendimento dos cálculos como dificuldade é significativamente maior que o número das outras dificuldades, há grande possibilidade de que a metodologia empregada seja predominantemente expositiva e centrada na operacionalização matemática, uma vez que esses métodos costumam dar pouca ênfase à interpretação da teoria e à relação do que se estuda com a prática e o contexto do aluno.

Esta pesquisa também buscou investigar as expectativas e aspirações dos estudantes diante das metodologias e recursos empregados em seus estudos. A Figura 7 mostra que a maioria dos alunos tem predileção pelo uso de experimentos, seja em sala de aula, seja no laboratório de ciências. Esses resultados destacam a importância que a experimentação tem no processo de ensino-aprendizagem, pois permite aos alunos analisar e materializar situações que de outro modo margeiam a abstração teórica. Além de garantir, segundo os $\mathrm{PCN}+$, "a construção do conhecimento pelo próprio aluno, desenvolvendo sua curiosidade e o hábito de sempre indagar” (BRASIL, 2006).

A Figura 8 mostra alguns recursos educacionais que os estudantes gostariam de fazer uso no estudo de Física. $O$ fato da distribuição de alunos ter sido heterogênea implica na necessidade de adoção do pluralismo metodológico que Laburú et al. (2003) propuseram para o ensino de Ciências. A diversidade na escolha dos recursos, além de aumentar a motivação dos alunos, também explora melhor suas habilidades, dando a eles a oportunidade de construir conhecimentos segundo suas especificidades.

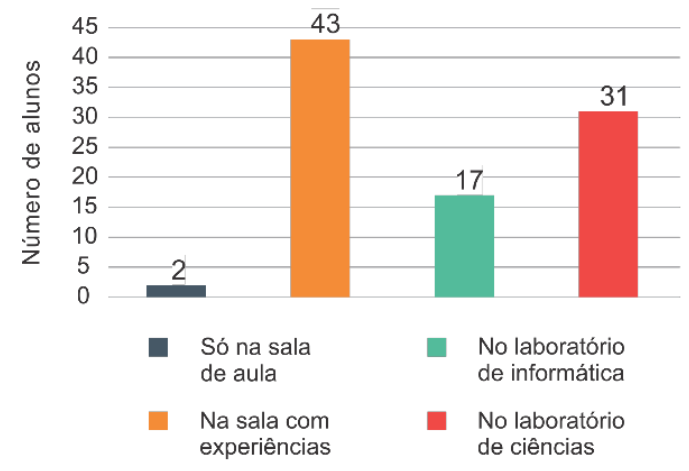

Figura 7 - Anseios na metodologia de estudo.

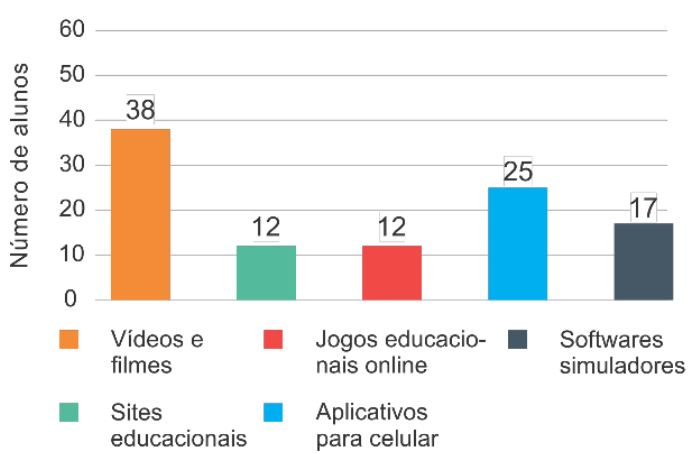

Figura 8 - Recursos educacionais que
os estudantes desejam usar.

$\mathrm{Na}$ Etapa 2, em que houve a intervenção na realidade dos estudantes por meio do uso de um simulador virtual, este trabalho buscou compreender a influência que os ODAs exerciam nos alunos, tanto em sua motivação como em sua aprendizagem. Quanto a motivação, por meio do método observacional, ficou claro o entusiasmo provocado pelo ODA. Porém, a influência não se limitou ao entusiasmo. Apesar de existir um roteiro, que norteava o uso do simulador, em vários momentos os alunos buscavam explorar outros recursos disponíveis no ODA. Assim, assumiram um papel mais ativo e protagonista que é fundamental para a construção de seu conhecimento. Como mencionado anteriormente, o uso de um simulador permite investigar situações 
que na vida real ofereceriam risco à vida. Durante o uso do ODA, a maioria dos estudantes buscou explorar situações assim, mesmo sem a indicação do roteiro. Outra influência positiva observada foi o comportamento deles diante das adversidades que surgiram. Apesar da presença de um professor, muitas dúvidas e problemas que surgiram foram solucionados por eles mesmos, num espírito interativo e cooperativo.

A influência do ODA utilizado na motivação dos estudantes também foi percebida nas impressões em que eles foram convidados a relatar sobre a aula que tiveram com o apoio dos simuladores virtuais. Todos elogiaram e/ou destacaram pontos que lhes chamaram atenção. De modo geral, destacaram a dinamicidade, a facilidade em aprender, o caráter prático, e a possibilidade de visualizar o que estava acontecendo. Uma aluna, por exemplo, escreveu: "Em relação a todas as aulas de física que já tive, essa foi uma das mais divertidas, foi mais fácil de aprender o conteúdo e, além disso, consegui ver a física por outro ângulo, sem aquela visão assustadora de tantos cálculos". É recorrente a redução do ensino de Física às técnicas operacionais matemáticas, porém, como destacado pela aluna, o uso de ODAs possibilitou a abordagem por outro ângulo, o que gerou maior ânimo e motivação em aprender.

Quanto a aprendizagem, o ODA também se mostrou uma ferramenta útil, uma vez que, com a atividade proposta no roteiro, esperava-se que os estudantes pudessem analisar e descrever os circuitos elétricos propostos, utilizando recursos oferecidos pelo simulador PhET. Os alunos foram capazes, não apenas de realizar medidas, mas também de analisar e descrever qualitativamente o circuito elétrico. A avaliação de sua aprendizagem foi bastante satisfatória diante da sua capacidade em prever resultados que poderiam ser obtidos através da operacionalização matemática de leis físicas. A atividade também permitiu avaliá-los quanto a construção, leitura e interpretação de gráficos e tabelas, que eles construíram com base nos resultados obtidos no simulador. Após a avaliação de suas respostas, os alunos responderam corretamente a atividade, obtendo um rendimento médio de $93 \%$, o que é um resultado excelente, principalmente porque demonstraram facilidade em interpretar e analisar resultados, reforçando a importância de ODAs como ferramentas propulsoras do ensino.

\section{Conclusão}

Nesta pesquisa, verificou-se que, apesar de muitos alunos terem a consciência da importância do ensino de Física, eles não têm afinidade com o seu estudo. O trabalho apontou ainda que a falta de afinidade, provavelmente, ocorre por não conseguirem dar significado aos conteúdos, visto que muitos estudantes não conseguiam relacionar a Física escolar com suas atividades do cotidiano, incluindo as tecnologias que utilizam. Um objetivo deste trabalho foi investigar a influência de ODAs no ensino de Física sobre motivação e aprendizagem dos alunos, em que os resultados sugeriram que os recursos digitais utilizados contribuem bastante para $o$ processo de ensino-aprendizagem, uma vez que os estudantes mostraram grande motivação em participar ativamente de sua aprendizagem, interagir e cooperar com colegas, explorar e realizar novas situações, ao mesmo tempo que mostraram ter adquirido uma boa compreensão, a nível qualitativo e quantitativo, do assunto proposto. Pode-se concluir também que, apesar dos ODAs terem se mostrado excelentes ferramentas e propulsores no ensino de Física, não constituem uma solução única e final para as dificuldades dos alunos. Os anseios estudantis, investigados nesta pesquisa deixaram claro a necessidade de se adotar um pluralismo metodológico. 
Este trabalho visou coletar dados que pudessem contribuir para a pesquisa científica na área de informática na educação. Acredita-se que os aspectos discutidos nesse estudo poderão ser relevantes para a continuidade de pesquisas sobre a influência do uso de ODAs no ensino de Física, especificamente do tipo simuladores, e como estes podem minimizar os desafios no processo de ensino-aprendizagem desta disciplina. A melhoria e promoção do ensino é um resultado a ser sempre buscado. Desse modo, é importante mais pesquisas sobre o uso de ODAs no ensino de Física quanto a sua eficácia e alcance educacional, sem reduzi-los a apenas um recurso lúdico.

\section{Agradecimentos}

Os autores agradecem o Centro de Referência Tecnológica (CERTEC) do Instituto Federal de Educação, Ciência e Tecnologia do Maranhão e o Centro de Ensino Joaquim Soeiro de Carvalho pelo apoio dado para a realização desta pesquisa.

\section{Referências Bibliográficas}

ARAÚJO, F. V. et al. Uma aplicação do software educacional PhET como ferramenta didática no ensino da eletricidade. Informática na educação: teoria \& prática, v. 18, n. 2, 2015.

AUSUBEL, D. P. Aquisição e retenção de conhecimentos: uma perspectiva cognitiva. Lisboa: Plátano, v. 1, 2003.

BOZELLI, F. C.; NARDI, R. Interações discursivas e o uso de analogias no ensino de física. Investigações em Ensino de Ciências, v.17, n.1, p. 81-107, 2012.

BRASIL, Ministério da Educação. Orientações Educacionais Complementares aos Parâmetros Curriculares Nacionais (PCN+). Ensino médio. Ciências da Natureza, Matemática e suas Tecnologias. Brasília, 2006. Disponível em: <http://portal.mec.gov.br/seb/arquivos/pdf/CienciasNatureza.pdf>. Acesso em 22 nov. 2019.

COELHO, J. A. P. M.; SOUZA, G. H. S.; ALBUQUERQUE, J. Desenvolvimento de questionários e aplicação na pesquisa em Informática na Educação. In: JAQUES, Patrícia Augustin; PIMENTEL, Mariano; SIQUEIRA; Sean; BITTENCOURT, Ig. (Org.) Metodologia de Pesquisa em Informática na Educação: Abordagem Quantitativa de Pesquisa. Porto Alegre: SBC, 2019. (Série Metodologia de Pesquisa em Informática na Educação, v. 2) Disponível em: <https://metodologia.ceie-br.org/livro-2>. Acesso em 09 dez. 2019.

CRUZ, P.; MONTEIRO, L. Anuário Brasileiro da Educação Básica (2019). São Paulo: Editora Moderna/Todos pela educação, 2019. Disponível em: <https://www.todospelaeducacao.org.br/_uploads/_posts/302.pdf>. Acesso em 22 nov. 2019.

FARDO, M. L. A gamificação como estratégia pedagógica: estudo de elementos dos games aplicados em processos de ensino e aprendizagem. Caxias do Sul: PPGEdu/UCS, 2013. 104p. Dissertação de Mestrado. 
GIRWIDZ, R.; THOMS, L-J.; POL, H.; LÓPEZ, V.; MICHELINI, M.; STEFANEL, A.; GRECZYLO, T.; MÜllER, A.; GREGORCIC, B.; HÖMÖSTREI, M. Physics teaching and learning with multimedia applications: a review of teacher-oriented literature in 34 local language journals from 2006 to 2015. International Journal of Science Education, v. 41, n. 9, pp. 1181-1206, 2019.

GREIS, L. K.; REATEGUI, E. Um simulador educacional para disciplina de física em mundos virtuais. Revista Novas Tecnologias na Educação, v. 8, n. 2, 2010.

LABURÚ, C. E.; ARRUDA, S.M.; NARDI, R. Pluralismo metodológico no Ensino de Ciências. Ciência \& Educação, v. 9, n. 2, p. 247-260, 2003.

MARTINS, E. F.; BASSO, M. V. A.. Concepção de Objetos Digitais de Aprendizagem para Combinatória nos Anos Iniciais. Revista Novas Tecnologias na Educação, v. 16, n. 1, 2018.

MATOS, J.D.V.; SILVA, J. R. C.; RIBEIRO, A. F. S.; GOMES, R. M. M.; FERREIRA, J. C.; MATOS, F. B. Aprendizagem Significativa por meio do Uso de TICs: Levantamento das Produções da Área de Ensino de 2016 a 2018. Revista Novas Tecnologias na Educação, v. 17, n 1, 2019.

MONTEIRO, M. A. A. O uso de tecnologias móveis no ensino de física: uma avaliação de seu impacto sobre a aprendizagem dos alunos. Revista Brasileira de Pesquisa em Educação em Ciências, v. 16, n. 1, p. 1-15, 2016.

MORAES, J. U. P. A visão dos alunos sobre o ensino de física: um estudo de caso. Scientia Plena, v. 5, n. 11, 2009.

MORTIMER, E. ; SCOTT, P. Atividade discursiva nas salas de aula de ciências: uma ferramenta sociocultural para analisar e planejar o ensino. Investigações em ensino de ciências, v. 7, n. 2, 2002.

NASCIMENTO, J. O.; NEIDE, I. G.; GONZATTI, S. E. M. Objetos de aprendizagem e o Microsoft Excel como ferramentas auxiliares no Ensino de Física. Revista Caderno Pedagógico, v. 13, n. 1, 2016.

SAVI, R.; ULBRICHT, V. R. Jogos digitais educacionais: benefícios e desafios. Revista Novas Tecnologias na Educação, v. 6, n. 1, 2008.

VALENTINI, C. B.; BISOL, C. A. Método para concepção de objetos de aprendizagem conceituais e atitudinais. Em Rede-Revista de Educação a Distância, v. 5, n. 1, 2018.

UNESCO. Ensino de Ciências: o futuro em risco. 2005. Disponível em: <https://unesdoc.unesco.org/ark:/48223/pf0000139948.locale=en>. Acesso em 22 nov. 2019.

ZARA, R. A. Reflexão sobre a eficácia do uso de um ambiente virtual no ensino de Física. In: II ENINED-Encontro Nacional de Informática e Educação, 2, 2011, Cascavel - PR, Brasil. 